\title{
Terapi Psikoreligius Dzikir Menggunakan Jari Tangan Kanan Pada Orang Dengan Gangguan Jiwa Di Rumah Sakit Jiwa Grhasia Daerah Istimewa Yogyakarta
}

\author{
Arif Munandar ${ }^{1}$, Kellyana Irawati ${ }^{2}$, Yonni Prianto ${ }^{3}$ \\ ${ }^{1}$ Mahasiswa Magister Keperawatan Peminatan Jiwa Universitas Muhammadiyah Yogyakarta \\ 2 Dosen Fakultas Keperawatan dan Ilmu Kesehatan Universitas Muhammadiyah Yogyakarta \\ ${ }^{3}$ Perawat Rumah Sakit Jiwa Grhasia Provinsi Daerah Istimewa Yogyakarta \\ Jl. Lingkar Selatan, Tamantirto, Kasihan, Bantul, DI Yogyakarta No. \\ Korespondensi:085253708078 e-mail:arifm96553@gmail.com
}

DOI: https://doi.org/10.33859/dksm.v10i1.451

\begin{abstract}
ABSTRAK
Latar belakang: Terapi psikoreligius dzikir menggunakan jari tangan kanan adalah suatu pengobatan secara kerohanian atau kebatinan agar kondisi kejiwaan klien serta akalnya berada dalam kondisi yang proporsional dengan cara dzikir agar senantiasa merasa dekat dengan-Nya, metode dzikirnya menggunakan jari tangan kanan

Tujuan: Terapi psikoreligius dzikir ini bertujuan untuk membuat hati dan pikiran lebih tenang yang tentunya akan membuat seseorang lebih fokus dalam melakukan aktivitas, emosi meluap-luap, rasa dendam, dan merangsang gelombang otak melalui pemijatan tangan pada ruas jari - jari tangan.

Metode: Penelitian ini menggunakan desain penelitian kualitatif. Populasi penelitian ini adalah orang dengan gangguan jiwa yang dirawat inap di rumah sakit jiwa Grhasia DIY. Sampel dalam penelitian ini sebanyak 5 orang.

Hasil: dari 5 orang dengan gangguan jiwa yang dilakukan terapi semuanya tidak ditemukan gangguan kognitif, dimana sebelum diberikan terapi diukur kemampuan kognitif dengan instrumen ScoRS, didapatkan 4 pasien tidak ada gangguan kognitif dan 1 pasien dengan gangguan kognitif ringan Kesimpulan: Terapi psikoreligius dzikir menggunakan jari tangan kanan sangat efektif dalam meningkatkan kemampuan kognitif pasien dengan skizofrenia dengan masalah keperawatan resiko perilaku kekerasan, halusinasi dan isolasi sosial.
\end{abstract}

Kata kunci : Psikoreligius Dzikir, Jari Tangan Kanan, dan Orang Dengan Gangguan Jiwa. 
Dinamika Kesehatan Jurnal Kebidanan dan Keperawatan Vol 10 No. 1 Juli 2019 ( ISSN: 2086-3454 EISSN: 2549-4058) url: http://ojs.dinamikakesehatan.unism.ac.id DOI : https://doi.org/10.33859/dksm.v10i1

Terapi Psikoreligius Dzikir Menggunakan Jari Tangan Kanan Pada Orang Dengan Gangguan Jiwa Di Rumah Sakit Jiwa Grhasia Daerah Istimewa Yogyakarta

\title{
Psychoreligious Therapy of Dhikr Using Right Hand Fingers In People With Mental Disorders In Grhasia Mental Hospital Daerah Istimewa Yogyakarta
}

\begin{abstract}
Background: Psychological therapy of dhikr using the right hand finger is a spiritual or kebatinan treatment so that the mental condition of the client and his mind are in a proportional condition by always dzikir to Allah SWT to always feel close to Him, as for the dhikr method using the right hand finger.
\end{abstract}

Purpose: This psychiatric dhikr therapy aims to make the heart and mind calmer which will certainly make a person more focused in doing activities, overflowing emotions, revenge, and stimulate brain waves through hand massage on the fingers.

Method: This study was conducted using a qualitative research design with a case study method. The population in qualitative research is termed a social situation in this study were people with mental disorders who were hospitalized in Grhasia DIY mental hospitals. The sample in this of 5 people.

Results: Of the 5 people with mental disorders who were treated for therapy all found no cognitive impairment, where before cognitive therapy was measured with ScoRS, 4 patients had no cognitive impairment and 1 patient with mild cognitive impairment

Conclusion: Psychiatric dzikir therapy using the right-hand finger is very effective in improving the cognitive abilities of patients with schizophrenia with nursing problems at risk of violent behavior, hallucinations and social isolation.

Keywords: Psychoreligious Dhikr, Right Hand Finger, and People with Mental Disorders 


\section{Pendahuluan}

Perkembangan diera globalisasi dan pesatnya kemajuan teknologi informasi memberikan dampak terhadap nilai-nilai sosial dan budaya pada masyarakat. Disisi lain, tidak semua orang mempunyai kemampuan yang sama untuk menyesuaikan dengan berbagai perubahan, serta mengelola konflik dan stres tersebut (Dermawan, 2017). Penderita gangguan jiwa di dunia diperkirakan akan semakin meningkat seiring dengan dinamisnya kehidupan masyarakat. Hampir 400 juta penduduk dunia menderita masalah gangguan jiwa. Satu dari empat anggota keluarga mengalami gangguan jiwa dan seringkali tidak terdiagnosis secara tepat sehingga tidak memperoleh perawatan dan pengobatan dengan tepat. Di rumah sakit jiwa Indonesia sekitar $70 \%$ mengalami resiko perilaku kekerasan (Muhtador, 2014). Terapi psikoreligius Dzikir menurut bahasa berasal dari kata "dzakar" yang berarti ingat. Dzikir juga di artikan "menjaga dalam ingatan". Jika berdzikir kepada Allah artinya menjaga ingatan agar selalu ingat kepada Alla ta"ala.
Dzikir menurut syara" adalah ingat kepada Allah dengan etika tertentu yang sudah ditentukan AlQur"an dan hadits dengan tujuan mensucikan hati dan mengagungkan Allah. Menurut Ibn Abbas ra. Dzikir adalah konsep, wadah, sarana, agar manusia tetap terbiasa dzikir (ingat) kepadaNya ketika berada diluar shalat. Tujuan dari dzikir adalah mengagungkan Allah, mensucikan hati dan jiwa, mengagungkan Allah selaku hamba yang bersyukur, dzikir dapat menyehatkan tubuh, dapat mengobati penyakit dengan metode Ruqyah, mencegah manusia dari bahaya nafsu (Arham, 2015). Teori keperawatan jean watson tentang "philosophy and science of caring", memahami bahwa manusia memiliki 4 cabang kebutuhan manusia, yang meliputi kebutuhan makanan dan cairan, kebutuhan eliminasi dan vertilasi, kebutuhan psikofisikial, kebutuhan seksual, kebutuhan psikososial sehingga dalam upaya mencapai kesehatan manusia seharusnya dalam keadaan sejahtera, baik fisik, mental, dan spiritual karena sejahtera merupakan keharmonisan antara pikiran, badan dan jiwa (Alligood, 2014). 
Dinamika Kesehatan Jurnal Kebidanan dan Keperawatan Vol 10 No. 1 Juli 2019 ( ISSN: 2086-3454 EISSN: 2549-4058) url: http://ojs.dinamikakesehatan.unism.ac.id DOI : https://doi.org/10.33859/dksm.v10i1

Terapi Psikoreligius Dzikir Menggunakan Jari Tangan Kanan Pada Orang Dengan Gangguan Jiwa Di Rumah Sakit Jiwa Grhasia Daerah Istimewa Yogyakarta

\section{Qs $\quad$ AL-Ahzab ayat 41

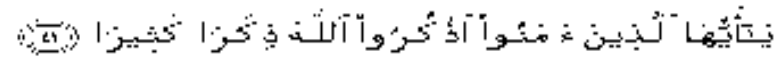

. Hadist Riwayat Abu Dawud dan At Tirmidzi Abdullah bin Amr berkata " saya melihat Rasulullah SAW berdzikir dengan melipatkan jari-jari menggunakan tangan kanannya”.

\section{Metode}

Penelitian ini merupakan penelitian kualitatif dengan pendekatan studi kasus yang bertujuan untuk memahami objek yang ditelitinya serta untuk menjelaskan bagaimana keberadaan dan mengapa kasus tersebut dapat terjadi, dimana peneliti ingin menjelaskan atau mengungkap makna konsep atau fenomena pengalaman yang didasari oleh kesadaran yang terjadi pada beberapa individu. Penelitian ini dilaksanakan pada tanggal 14 Januari sampai 19 Januari 2019. Penelitian ini dilakukan di Wisma Arjuna RSJ Grhasia DIY pada tanggal 14 Januari 30 Maret - 19 Januari 2019. Penelitian ini menggunakan desain deskriptif kualitatif dengan pendekatan proses keperawatan (nursing proses). Populasi penelitian adalah pasien dengan halusinasi pendengaran, dengan kriteria inklusi pasien dengan diagnosa resiko perilaku kekerasan, halusinasi dan isolasi sosial dengan jumlah sampel sebanyak 5 orangg. Pengambilan sampel dengan Purposive Sampling. Instrumen penelitian menggunakan Pedoman Wawancara, Buku dan alat tulis. Teknik Analisa menggunakan transkrip wawancara. Peneliti memberikan tindakan Dzikir ketika pasien ketika pasien selesai melaksanakan sholat wajib. Prosedur pelaksanaan terapi psikoreligius dzikir, yaitu Pastikan peserta dalam keadaan berwudhu, Peserta duduk bersila dengan nyaman, tenang, khusyu, berpakaian bersih dan rapi, Posisi duduk menghadap ke arah kiblat, Sebelum mulai, terapis memimpin doa dan kegiatan ini akan berlangsung selama 60 menit, Terapis akan memperagakan tata cara berdzikir menggunakan jari tangan kanan dengan baik dan benar, Awali dzikir dengan istigfar (Astaqfirullahal'adzim) sebanyak 3 kali, dilanjutkan dengan tasbih (Subhannallah) 33 kali, tahmid (Alhamdulillah) 33 kali, dan takbir (Allahu akbar) 33 kali dan ditutup dengan kalimat tahlil (laillahaillahlah 
Dinamika Kesehatan Jurnal Kebidanan dan Keperawatan Vol 10 No. 1 Juli 2019 ( ISSN: 2086-3454 EISSN: 2549-4058) url: http://ojs.dinamikakesehatan.unism.ac.id DOI : https://doi.org/10.33859/dksm.v10i1

Terapi Psikoreligius Dzikir Menggunakan Jari Tangan Kanan Pada Orang Dengan Gangguan Jiwa Di Rumah Sakit Jiwa Grhasia Daerah Istimewa Yogyakarta

muhammaddarasulullah) sebanyak 1 kali, Menggunakan tangan kanan, Ibu jari (jempol) digunakan sebagai penunjuk ruas jari dan 1 jari dihitung 7 kecuali ibu jari dihitung 5, Jangan hitung ruas jarinya, tetapi hitunglah ujung ruas jari kiri dan kanan + ujung jari dan Terapis mengevaluasi dan menutup kegiatan dengan doa.

\section{Hasil}

Dari 5 orang dengan gangguan jiwa yang dilakukan terapi semuanya tidak ditemukan gangguan kognitif, dimana sebelum diberikan terapi diukur kemampuan kognitif dengan instrumen ScoRS (Schizophrenia cognition rating scale), didapatkan 4 pasien tidak ada gangguan kognitif dan 1 pasien dengan gangguan kognitif ringan.

Tabel 1 kemampuan kognitif orang dengan gangguan jiwa di RSJ Grhasia DIY sebelum dan sesudah diberikan terapi psikoreligius dzikir menggunakan jari tangan kanan

\begin{tabular}{|l|l|l|l|l|l|}
\hline $\begin{array}{l}\text { Karekter } \\
\text { istik }\end{array}$ & P1 & P2 & P3 & P4 & P5 \\
\hline Umur & 34 & 34 & 32 & 30 & 40 \\
\hline $\begin{array}{l}\text { Jenis } \\
\text { kelamin }\end{array}$ & $\begin{array}{l}\text { Laki - } \\
\text { laki }\end{array}$ & $\begin{array}{l}\text { Laki - } \\
\text { laki }\end{array}$ & $\begin{array}{l}\text { Laki - } \\
\text { laki }\end{array}$ & $\begin{array}{l}\text { Laki - } \\
\text { laki }\end{array}$ & $\begin{array}{l}\text { Laki - } \\
\text { laki }\end{array}$ \\
\hline $\begin{array}{l}\text { Pendidik } \\
\text { an }\end{array}$ & SMA & S1 & S1 & SMA & SMA \\
\hline Agama & Islam & Islam & Islam & Islam & Islam \\
\hline $\begin{array}{l}\text { Pekerjaa } \\
\text { n }\end{array}$ & $\begin{array}{l}\text { Wiras } \\
\text { wasta }\end{array}$ & $\begin{array}{l}\text { Wiras } \\
\text { wasta }\end{array}$ & $\begin{array}{l}\text { Wiras } \\
\text { wasta }\end{array}$ & $\begin{array}{l}\text { Tidak } \\
\text { bekerja }\end{array}$ & $\begin{array}{l}\text { Tidak } \\
\text { bekerja }\end{array}$ \\
\hline Sebelum & $\begin{array}{l}\text { Norm } \\
\text { al }\end{array}$ & Normal & Normal & Normal & Ringan \\
\hline Sesudah & $\begin{array}{l}\text { Norm } \\
\text { al }\end{array}$ & Normal & Normal & Normal & Normal \\
\hline
\end{tabular}

\section{Diskusi}

Gambaran kemampuan kognitif orang dengan gangguan jiwa di jelaskan dalam bentuk tema-tema yang diperoleh dari hasil analisis karakteristik partisipan dan hasil wawancara terhadap partisipan. Tema 1 yaitu Perubahan emosi, Perubahan emosi dalam penelitian ini ditunjukkan oleh adanya gejala depresi, kecemasan, kemarahan, dan harga diri rendah. Bentuk perubahan emosi lain yang terjadi pada masyarakat korban adalah timbulnya perasaan rendah diri, Tema 2 adalah perubahan kognitif, temuan penelitian ini menyatakan adanya perubahan kognitif yang terjadi yaitu penurunan daya pikir. Adanya perubahan kognitif pada pasien seperti tidak mampu berpikir jernih, menjadi ragu-ragu karena tidak ada kepastian, dan pikiran mereka terpecahpecah dengan persoalan-persoalan lain yang mereka hadapi ini sesuai dengan temuan Norris, Muhtador (2014) bahwa salah satu dampak dari masalah keperawatan seperti resiko perilaku kekerasan, halusinasi dan isolasi sosial adalah terjadinya perubahan kognitif dengan ciri pikiran kacau, salah 
Dinamika Kesehatan Jurnal Kebidanan dan Keperawatan Vol 10 No. 1 Juli 2019 ( ISSN: 2086-3454 EISSN: 2549-4058)

url: http://ojs.dinamikakesehatan.unism.ac.id DOI : https://doi.org/10.33859/dksm.v10i1

Terapi Psikoreligius Dzikir Menggunakan Jari Tangan Kanan Pada Orang Dengan Gangguan Jiwa Di Rumah Sakit Jiwa Grhasia Daerah Istimewa Yogyakarta

persepsi, menurunnya kemampuan untuk mengambil keputusan, menurunnya daya konsentrasi dan daya ingat, mengingat hal-hal yang tidak menyenangkan, dan menyalahkan diri sendiri. Tema 3 mengenai mekanisme koping temuan dalam penelitian ini, mekanisme koping yang digunakan dapat dikategorikan mekanisme adapatif dan maladaptif atau tidak efektif. Mekanisme koping yang adapatif di antaranya berdo'a (pendekatan spiritual), memendam perasaan (represi) dan mengalihkan perhatian agar dapat melupakan masalah yang terjadi, atau dengan meminta bantuan saudara. Sementara yang tidak efektif seperti menghujat, mengancam melakukan demonstrasi terus, membuntu atau memblokir jalan, dan melampiaskan emosi kepada anakistrinya meskipun cara maladaptif ini hanya bersifat sementara. Tema 4 adalah perubahan fungsi keluarga, Temuan dalam penelitian ini, masyarakat korban mengalami perubahan fungsi keluarga, yaitu perubahan pada fungsi sosial dan fungsi ekonomi. Fungsi sosial terkait dengan hubungan kekeluargaan yang merenggang. Tema 5 adalah Perubahan hubungan sosial kemasyarakatan. Hasil penelitian menunjukkan solidaritas masyarakat korban melemah dan kepedulian sosial menurun. Menurut Arham (2015), dampak disintegrasi sosial, tercerai-berainya masyarakat, dan tidak bisa dikuantifikasi.

\section{Kesimpulan}

Terapi psikoreligius dzikir menggunakan jari tangan kanan sangat efektif dalam meningkatkan kemampuan kognitif pasien dengan skizofrenia dengan masalah keperawatan resiko perilaku kekerasan, halusinasi dan isolasi sosial. Penerapan terapi ini perlu dijadikan program rutin rumah sakit jiwa sebagai terapi aktivitas sosial maupun kegiatan harian pasien di ruang perawatan, khusus pada ruangan pasien yang dalam tahap maitenance. 
Dinamika Kesehatan Jurnal Kebidanan dan Keperawatan Vol 10 No. 1 Juli 2019 ( ISSN: 2086-3454 EISSN: 2549-4058)

url: http://ojs.dinamikakesehatan.unism.ac.id DOI : https://doi.org/10.33859/dksm.v10i1

Terapi Psikoreligius Dzikir Menggunakan Jari Tangan Kanan Pada Orang Dengan Gangguan Jiwa Di Rumah Sakit Jiwa Grhasia Daerah Istimewa Yogyakarta

\section{Daftar pustaka}

Alligood, M.R. 2014. Nursing Theorists and Their Work, 8th ed. Missouri: Mosby Elsevier.

Arham, MU. 2015. Terapi spiritual melalui dzikir pada santri gangguan jiwa di PP Al Qadir Cangkringan Yogyakarta. Yogyakarta: FKD UIN Sunan Kalijaga.

Dermawan, D. 2017. Pengaruh Terapi Psikoreligius: Dzikir Pada Pasien Halusinasi Pendengaran di RSJD dr. Arif Zainudin Surakarta. Volume 15 no.1. ejournal@stikespku.ac.id

Hadist riwayat Abu Dawud, II/8, At Tirmidzi V/521, dan Shahihul Jami, IV/271, No. 4865.
Hidayatulloh, dkk. 2013. Al quran dan Tajwid kode transliterasi. Bekasi : Cipta bagus segara

Hussein, JW. 2016. The social psychological and phenomenological construct of spirituality in the culture of dhikr in Eastern Ethiopia. https://doi.org/10.11771135406716672415, 0(0) 1-23. SAGE.

Keefe, et al. 2015. Reliability, validity and treatment sensitivity of the Schizophrenia Cognition Rating Scale. http://dx.doi.org/10.1016/j. 176-184 Elsevier.

Muhtador. 2014. Pemaknaan Ayat Al-Quran Dalam Mujahadah: Studi Living Al Quran Di PP Al-Munawwir Krapyuak Komplek Al Kandiyas" Jurnal Penelitian. Vol.8 No. 1 